\title{
Synthesis and Study of Thermo Stability Properties of Novel Polyamides
}

\author{
Ali Sadeghinia and Hossein Mighani* \\ Department of Chemistry, Faculty of Science, Golestan University, Gorgan, Iran
}

*Corresponding author: Hossein Mighani, Department of Chemistry, Faculty of Science, Golestan University, Gorgan, P.O. Box 155, Iran, Tel: +981732245964; E-mail: hossein.mighani@gu.ac.ir

Received date: April 22, 2018; Accepted date: May 07, 2018; Published date: May 11, 2018

Copyright: ( 2018 Sadeghinia A, et al. This is an open-access article distributed under the terms of the Creative Commons Attribution License, which permits unrestricted use, distribution, and reproduction in any medium, provided the original author and source are credited.

\begin{abstract}
Aromatic and aliphatic diamines are one of the main components in polyamides, polyimides, polyurea and polyurethanes. To prepare high performance and well featured materials, attempts is directed to the novel diamine synthesis routes in which soluble thermo-resistant, soluble and easy process polymers are obtained. To solubility improvement and decreasing the glass transition temperature, existing flexible bonds in polymer repeating unit are necessary. These bonds decrease the internal rotational energies. Using heterocyclic rings or introducing of polar functional groups such as amide in the main synthetic polymer chain results in convenient polarity and solubility of polymer. Until now, massive investigations have been conducted to prepare aromatic monomers with high solubility and processing capabilities. In the current study, our main aim is to prepare diamines which are applicable in thermo-resistant polymers including polyamide, polyimide, polyurea and polyurethanes.
\end{abstract}

Keywords: Diamine; Thermo-resistant polymer; Polyamide; Polyimide; Polyurethane

\section{Introduction}

Amines being a main component of amino acids, peptides and containing nitrogen compounds are the most abundant organic molecules. Primary and secondary amines are less acidic and form weaker hydrogen bonds with alcohols and ethers compare to alkaloids. On the contrary, they are stronger base and nucleophiles compared to the alcohols and ethers. Diamines are amines with two functional amine groups. Hexamethylene diamine is an important amine which is used in nylon manufacture and it reacts with adipic acid to produce nylon 6, 6. This nylon is used in socks, stretch cloths and textile fibers. Many investigations have been performed on diamines that some of them are referred in continue. Effect of EDTA and Municipal solid waste compost on different amount of lead and cadmium in soil and plant decontamination of these elements by sunflower was investigated [1]. A cationic catalyst of iron complex has catalyzed an amination of aryl-aziridine to high yield production a diamine. This method is compatible with both existing functional groups in amine and aziridine [1]. Amination of meso-en-phenyl aziridineis progressed by $1 \%$ of mentioned catalyst to produce a diamine with high yield [2]. Activating of aziridine thorough a $\mathrm{SN}_{2}$ ring opening reaction by means of Bromo-aniline in presence of palladium as catalyst and forming an intermolecular $\mathrm{C}-\mathrm{N}$ bond and selecting a stereo selective path, one can prepare racemic and non-racemic tetrahydroquinoxaline [3]. Dinuclear iodine (III) can promote intermolecular amidation of alkanes. This reagent can progress the reaction by formation of chiral imido-iodine intermediate [4]. Using copper chloride as catalyst and ditertiary butyl thiaaziridionine as nitrogen source provide a mild condition to high efficient amidation of olefins [5]. Wide range of olefins are prone to participate in diamination reaction through allylic and homo-allyliccarbon activation. This stereoselective reaction is performed using ditertiary butyl aziridinone as nitrogen source and trephenyl palladium as catalyst [6-8]. Asymmetric diamination of a dien alkyl N, N-di-tertiary-butyl thiadiaziridine1,1- dioxide in presence of palladium and chiral phosphoramidite ligand results in cyclic sulphamide [9]. Diamination of non-reactive alkenes with enfluorobenzene sulfonamide (NFBS) as nitrogen donor was performed [10]. Diamination through an intermolecular reaction catalyzed by palladium led to urea formation in which oxidative conversion of alkene in presence of iodosobenzene as oxidative reagent is the main reason of urea formation [11]. In this study, we deal with synthesis and characterization of novel monomer which are used in various polymers. Diol, diacid, diisocyanate and diamines are typical monomers which are applicable in preparation of different polymers such as polyamide, polyurethane and polyimides. Diamines occupied here, are among of the most important monomers which have been used during recent years. There are two kinds of diamines: aliphatic and aromatic diamines. Polymers prepared from aromatic monomers are commonly more thermo-resistant and less soluble. So, semiaromatic diamines seem to be more soluble than aromatic ones. Therefore, synthesis of semi-aromatic diamines is the aim of many investigations, as they have suitable solubility and thermal resistance.

In addition, novel polyamides having high thermal resistivity were synthesized successfully. In addition to high thermal resistance, these polyamides had improved solubility and showed high processing properties. To synthesis these polyamides, first a diamine with welldefined precursor was prepared and then reacted with different acyl chloride and dicarboxylic acids to obtain these novel polyamides. It was clear that such thermal resistivity is due to amide structure and rigid phenyl rings. Also, solubility and processability will improve by introducing aliphatic groups into the polyamide structure.

\section{Experimental}

\section{Materials and instruments}

Nitric acid Fuming, Benzyl, 4-Nitrobenzaldehyde, Ammonium acetate, Hydrazine hydrate, dichloride acid and solvents were purchased from Merck Co, and Fluorene prepared from Sigma Aldrich Co ${ }^{1} \mathrm{H}-\mathrm{NMR}$ and ${ }^{13} \mathrm{C}$-NMR spectra were recorded on a $500 \mathrm{MHz}$ 
Bruker Advance Dpx400 apparatus using DMSO-d6 as solvent and tetra methyl silane as standard. FTIR spectra were recorded by a FT-IR Spectrometer Spectrum RXI from Perkin Co. The CHNS-Rapid Heraeus was used for elemental analysis. Thermal gravimetric analysis was performed by TGA device model PL-TGA from Polymer Laboratories. Inherent viscosity was measured with an Ubbelohde suspended-level viscometer at room temperature and melting point was measured using Electrothermal model Engineering LTD.

\section{Monomer synthesis}

Synthesis of 2, 7-dinitrofluorene: Initially, mixture of $10 \mathrm{~g}(0.06 \mathrm{~mol})$ fluorene and $50 \mathrm{ml}$ glacial acetic acid at $0-5^{\circ} \mathrm{C}$ were entered a threeneck balloon equipped with mechanical stirrer while stirring for $0.5 \mathrm{~h}$ (Scheme 1). While the solution was stirring, $50 \mathrm{ml}$ fuming nitric acid was added during $45 \mathrm{~min}$. After nitric acid addition, reaction temperature ascended to $65^{\circ} \mathrm{C}$ and after that mixture allowed to cool down and stand for a night. An orange precipitate is formed through this procedure. Next, the mixture was transferred to the $500 \mathrm{ml}$ water/ice and stirred for $1 \mathrm{~h}$. The mixture was filtered and washed several times with deionized water. The product was dissolved in 150 $\mathrm{ml}$ chloroform and after washing several times with water and salt, the orange phase was separated and dried with magnesium sulfate. After solvent removal, orange viscose phase was separated and dissolved in $100 \mathrm{ml}$ hexane. After placing the container into ice-water, the yellow precipitate which is related to 2, 7-dinitro fluorine was appeared. Yield of reaction was $79 \%$ and melting point was about $295-300^{\circ} \mathrm{C}$.

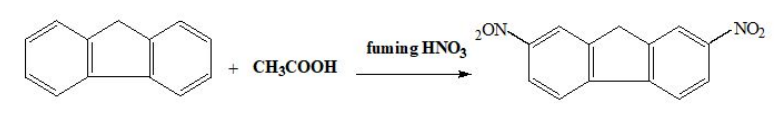

Scheme 1: Structure of 2, 7-dinitrofluorene.

Synthesis of 2, 7- diaminofluorene: Second step is the reduction of dinitro product. Mixture of $7 \mathrm{~g}(0.028 \mathrm{~mol}) 2$, 7-dinitrofluorene, $0.5 \mathrm{~g}$ $\mathrm{Pd} / \mathrm{C}(5 \%)$ and $150 \mathrm{ml}$ absolute ethanol were added to a three-neck balloon equipped with mechanical stirrer while refluxing (Scheme 2). Then $20 \mathrm{ml}$ hydrazine hydrate $85 \%$ mixed with 25 methanol was introduced into the balloon dropwise during $1.5 \mathrm{~h}$. Mixture was refluxed for $2 \mathrm{~h}$ and another $0.1 \mathrm{~g}$ of fresh catalysis added at different time distances during the refluxing time. After reaction being completed, mixture was filtered, and resultant solution was transferred to cold water where 2, 7-diaminofluorene precipitated. After washing with water, final product was dried at $60^{\circ} \mathrm{C}$ for $5 \mathrm{~h}$. Yield of reaction was about $94 \%$ with melting point of $160-163^{\circ} \mathrm{C}$.

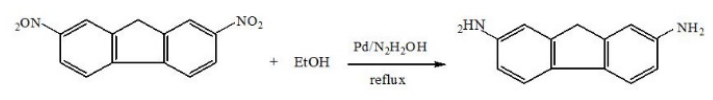

Scheme 2: Structure of 2, 7-diaminofluorene.

Fluorene based dinitro synthesis: To prepare fluorene based dinitro, $1 \mathrm{mmol} 2,7$ diaminofluorene, $2 \mathrm{mmol}$ benzyl, $2 \mathrm{mmol}$ ammonium acetate were entered a three-neck balloon equipped with stirrer and condenser and $10 \mathrm{ml}$ acetic acid added as well (Scheme 3). The mixture was refluxed for $12 \mathrm{~h}$ at $120^{\circ} \mathrm{C}$. After cooling, filtering and washing with methanol, the final product was dried at $90^{\circ} \mathrm{C}$ for $5 \mathrm{~h}$. Obtained yellow precipitate melting point was $335-340^{\circ} \mathrm{C}$.

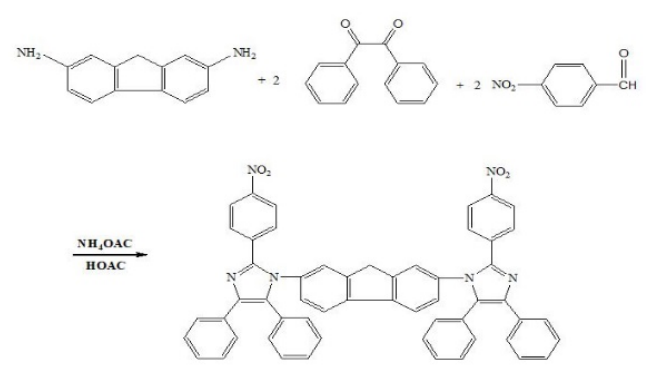

Scheme 3: Structure of dinitro based of fluorene.

Fluorene based diamine synthesis: Mixture of $7 \mathrm{~g}$ (0.028 mol) 2,7dinitrofluorene, $0.5 \mathrm{~g}$ palladium/C (5\%) and $150 \mathrm{ml}$ ethanol was transferred to a $250 \mathrm{ml}$ balloon equipped with stirrer and condenser while refluxing (Scheme 4).

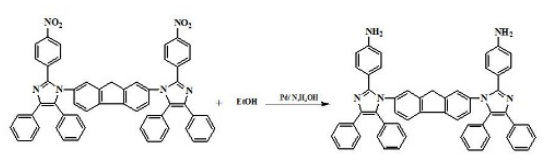

Scheme 4: Structure of Schiff base diamine monomer $\left(\mathrm{LH}_{4}\right)$.

$20 \mathrm{ml}$ hydrazine hydrate (85\%) dissolved in $25 \mathrm{ml}$ ethanol was drop wise added to the reaction container during $1.5 \mathrm{~h}$. The mixture was refluxed for $2 \mathrm{~h}$ and another $0.1 \mathrm{~g}$ off rest catalysis added at different time distances during the refluxing time. After filtering, obtained precipitate was dried at $60^{\circ} \mathrm{C}$ for $5 \mathrm{~h}$. Then the precipitate was dissolved in $100 \mathrm{ml} \mathrm{THF}$ and refluxed at $70^{\circ} \mathrm{C}$. After filtering, the resultant solution was transferred to the cold water and opaque white crystallized product appeared. Finally, precipitate was dried at $60^{\circ} \mathrm{C}$ for $5 \mathrm{~h}$. Yield of reaction was $78 \%$ and the melting point was about $245-248^{\circ} \mathrm{C}$

Polyamide synthesis: For the synthesis of polyamides, dicarboxylic acid and di-acyl chloride were used. Schematic of synthesis procedure is shown in Scheme 5.

Polyamide synthesis via dicarboxylic acid: Firstly, $2 \mathrm{mmol}$ flourene based diamine and 2 mmol biphenyl-4, 4-dicarboxylic acid were transferred into a two-necked balloon equipped with condenser, under nitrogen atmosphere and then $4.1 \mathrm{mmol}$ triphenyl phosphate which have already been dissolved in a solvent mixture (30 $\mathrm{ml} \mathrm{NMP}$ and $6 \mathrm{ml}$ pyridine) containing dissolved $\mathrm{LiCl}(0.6 \mathrm{~g})$ and $\mathrm{CaCl}_{2}(1.8 \mathrm{~g})$ was added to the reaction vessel. The mixture was stirred under nitrogen for $7 \mathrm{~h}$ at $110^{\circ} \mathrm{C}$ then the mixture was transferred into the methanol and filtered, after refluxing by methanol dried at $120^{\circ} \mathrm{C}$. Reaction yield was $90 \%$ and melting point was over $400^{\circ} \mathrm{C}(\mathrm{PA} 1)$. 


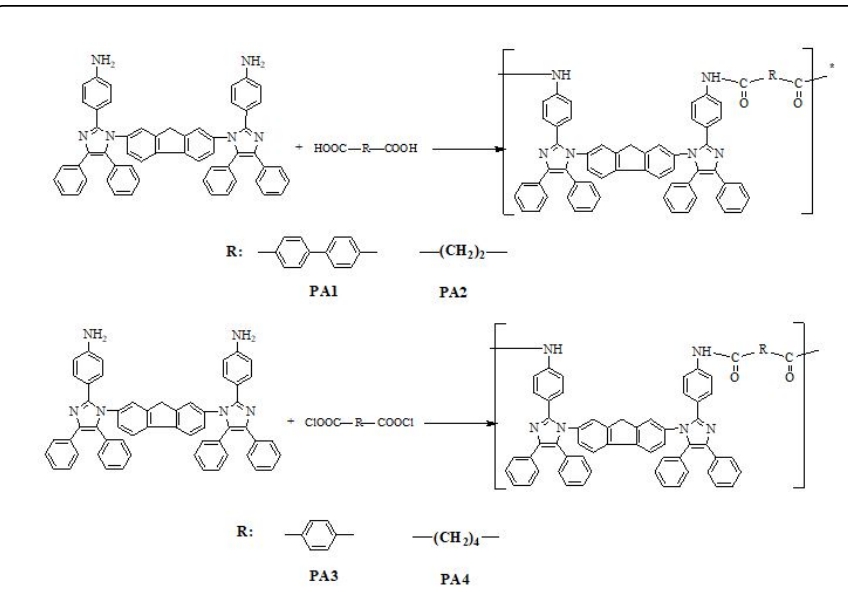

Scheme 5: Structure of polyamides.

Polyamide synthesis by di-acyl chloride: Triethyl amine was added to a $100 \mathrm{ml}$ balloon containing $2 \mathrm{mmol}$ dissolved diamine in $20 \mathrm{ml}$ THF at $0^{\circ} \mathrm{C}$ under nitrogen atmosphere while stirring, $0.5 \mathrm{~g}$ and then 2 mmol dissolved isophthaloyl dichloride in $10 \mathrm{ml} \mathrm{THF}$, was added to the reaction mixture dropwise. After $3 \mathrm{~h}$ stirring at room temperature, the mixture was transferred into the cold water where the product filtered and washed with $\mathrm{NaHCO}_{3}$ and water. Finally, the obtained polymer was dried at $70^{\circ} \mathrm{C}$. The final product melting point was $380^{\circ} \mathrm{C}$ (PA3).

In another synthesis, we prepared the polyamide in a similar way of PA3, but instead of isophthaloyl dichloride, adipoyl dichloride (PA4) was used.

\section{Results and Discussion}

\section{Monomer synthesis and characterization}

The monomers, 1-2, were prepared according to the method given in the literature. The characteristics data obtained from FTIR and ${ }^{1} \mathrm{H}-$ NMR spectra as listed in Table 1, confirmed the structures illustrated in Schemes 1-4. The interesting absorption bands in the FTIR spectrum of monomer 4, are: $3452 \mathrm{~cm}^{-1}$ and $3369 \mathrm{~cm}^{-1}$ (related to stretching vibration of $\mathrm{NH}_{2}$ ) (Figure 1). Aromatic $\mathrm{C}-\mathrm{H}$ vibration peak appear on $3028 \mathrm{~cm}^{-1}$. Corresponding stretching vibration peaks of $\mathrm{C}=\mathrm{C}$ are on 1473 and $1382 \mathrm{~cm}^{-1}$ and peaks on 1290 and $1617 \mathrm{~cm}^{-1}$ are assigned to $\mathrm{C}-\mathrm{N}$ and $\mathrm{C}=\mathrm{O}$ vibrations.

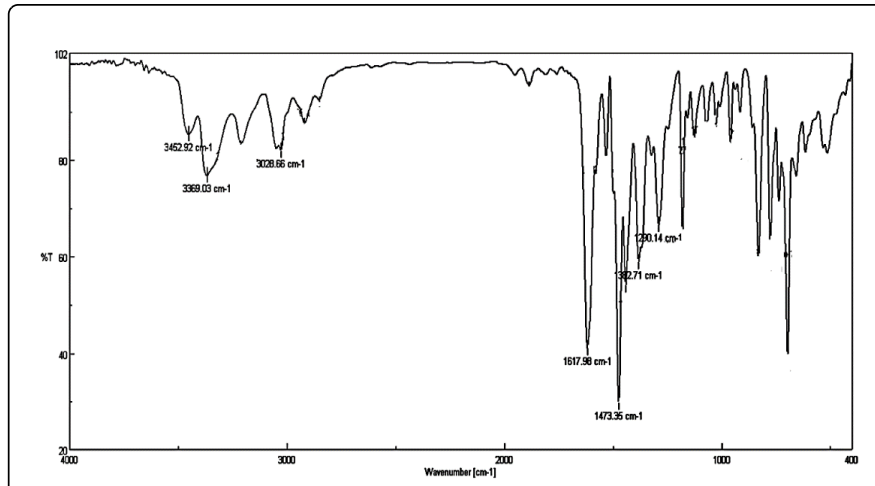

Figure 1: FTIR spectra of $\mathrm{LH}_{4}$.

In ${ }^{1} \mathrm{H}$-NMR spectrum monomer $4\left(\mathrm{LH}_{4}\right)$, of Figure 2, the peak on $5.2 \mathrm{ppm}$ is related to $\mathrm{NH}_{2}$. With envisaging the fact that, two $\mathrm{NH}_{2}$ groups are present in structure and if the peak areas relating to these two $\mathrm{NH}_{2}$ groups are considered 4 and other peaks evaluated regard to this peak, one can conclude that, the peaks higher than $6 \mathrm{ppm}$ are related to aromatic hydrogen's which integration of these peak areas is equal to 34 verifying the number of aromatic hydrogen's. The peak on $2 \mathrm{ppm}$ is related to methylene hydrogen's which has been split due to diastereotopic effect. Integration of peak areas was 2, proving the number of methylene hydrogen's.

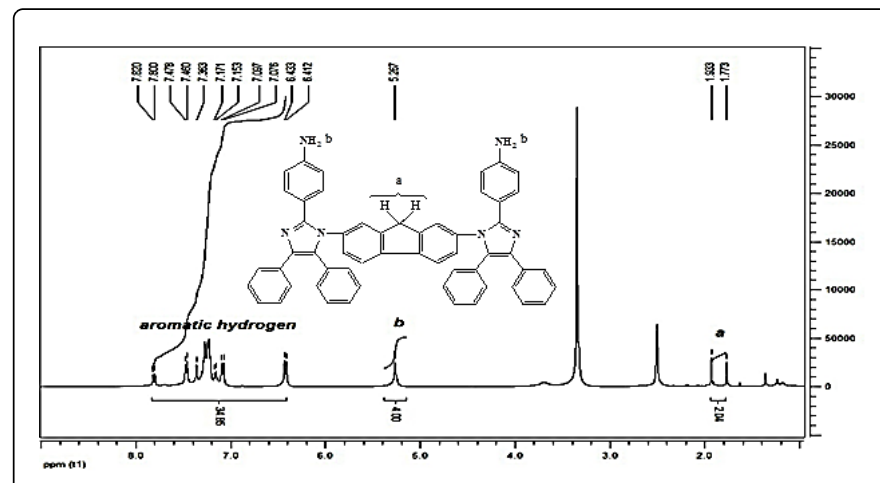

Figure 2: ${ }^{1} \mathrm{H}-\mathrm{NMR}$ spectrum of $\mathrm{LH}_{4}$.

As shown in Figures 3a and $3 \mathrm{~b}$, in ${ }^{13} \mathrm{C}-\mathrm{NMR}$ spectrum, a peak on $30.38 \mathrm{ppm}$ is related to $\mathrm{CH}_{2}$, and the peaks in region of $113-148 \mathrm{ppm}$, is related to aromatic carbons. 
Citation: Sadeghinia A, Mighani H (2018) Synthesis and Study of Thermo Stability Properties of Novel Polyamides. J Enviorn Anal Chem 5: 241.

Page 4 of 6

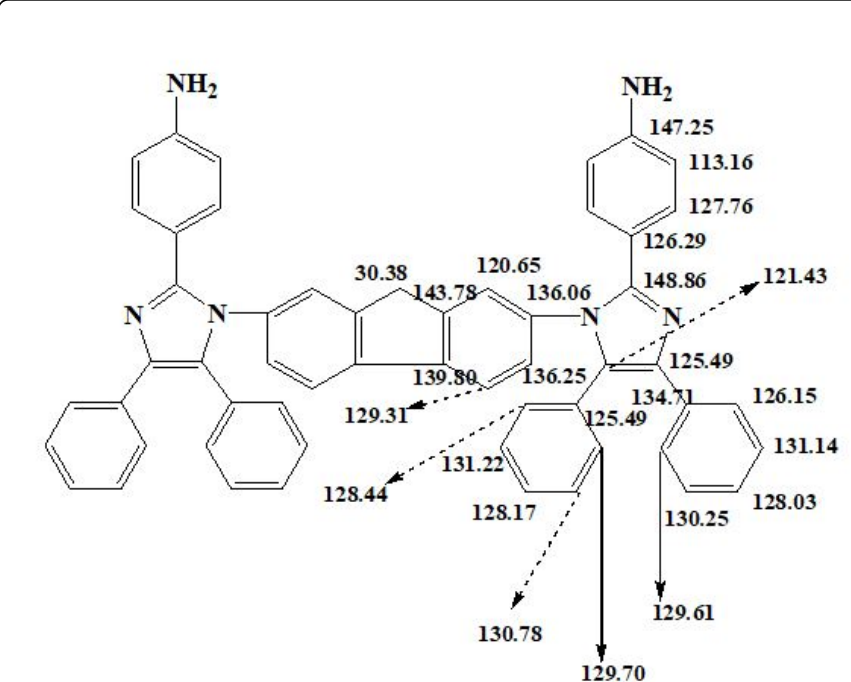

Figure 3a: ${ }^{13} \mathrm{C}-\mathrm{NMR}$ spectrum of $\mathrm{LH}_{4}$.

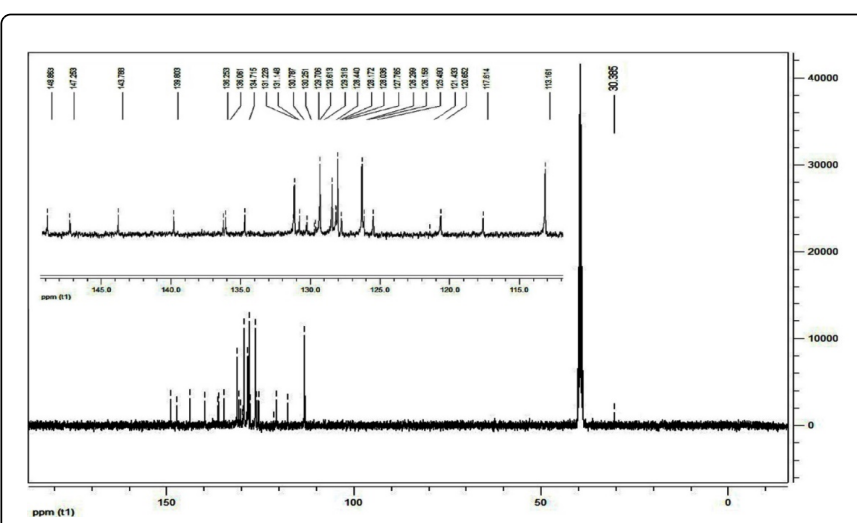

Figure 3b: ${ }^{13} \mathrm{C}-\mathrm{NMR}$ spectrum of $\mathrm{LH}_{4}$.

Polyamides synthesis and characterization: As illustrated in Scheme 5 , the polyamides were prepared by polycondenstion of $\mathrm{LH}_{4}$ with aliphatic and aromatic dicarboxylic acid dichlorides under $\mathrm{N}_{2}$ atmosphere. Elemental analysis of PA4 is presented in Table 2, That is in good agreement with the predicted structure. The inherent viscosity $[\eta]$ inh of the polyamides determined at concentration of $0.125 \mathrm{~g} / \mathrm{dL}$ in NMP and $25^{\circ} \mathrm{C}$ was in the range of $0.31-0.57 \mathrm{dl} / \mathrm{g}$. FTIR spectra of the polyamides showed characteristic absorption bands in the regions of $3298-3362 \mathrm{~cm}^{-1}, 1629-1661 \mathrm{~cm}^{-1}$ and $1269-1285 \mathrm{~cm}^{-1}$, related to the $\mathrm{N}-\mathrm{H}, \mathrm{C}=\mathrm{O}$ and $\mathrm{C}-\mathrm{N}$ stretching, respectively. ${ }^{1} \mathrm{H}-\mathrm{NMR}$ spectra of PA1 and PA2 are shown in Figures 4 and 5. ${ }^{1} \mathrm{HNMR}$ spectrum of PA1 resembles to ${ }^{1} \mathrm{HNMR}$ of monomer 4 but chemical shift in protons of methyl and amide groups in PA1 can attribute to the polymer formation. Peaks at 1.9 and $2.1 \mathrm{ppm}$ are related to the methyl protons and peak at $588 \mathrm{ppm}$ verifies the amide protons. Peak of aromatic hydrogens appears in region of 7.15 to $7.48 \mathrm{ppm}$. For PA2, peaks at 0.93 and $1.3 \mathrm{ppm}$ are related to aromatic methylene groups and a peak at $2.3 \mathrm{ppm}$ corresponds to the methylene in amide structure. Peaks at 6.8 and 7.8 pertain to aromatic hydrogens and a peak at $10.7 \mathrm{ppm}$ relates to amide hydrogens. Chemical shift toward down fields is due to hydrogen bond formation of amide group.

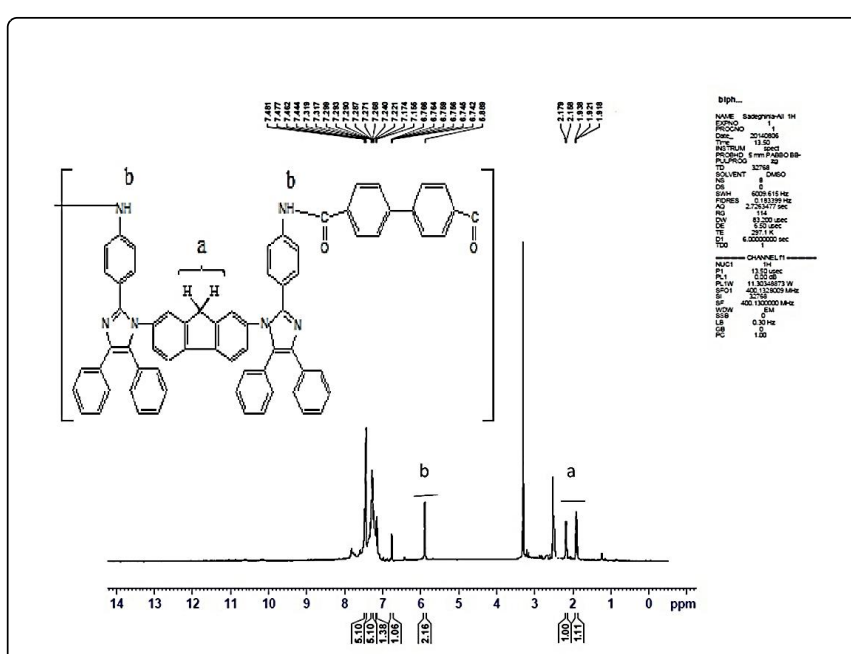

Figure 4: ${ }^{1} \mathrm{H}-\mathrm{NMR}$ spectrum of PA1.

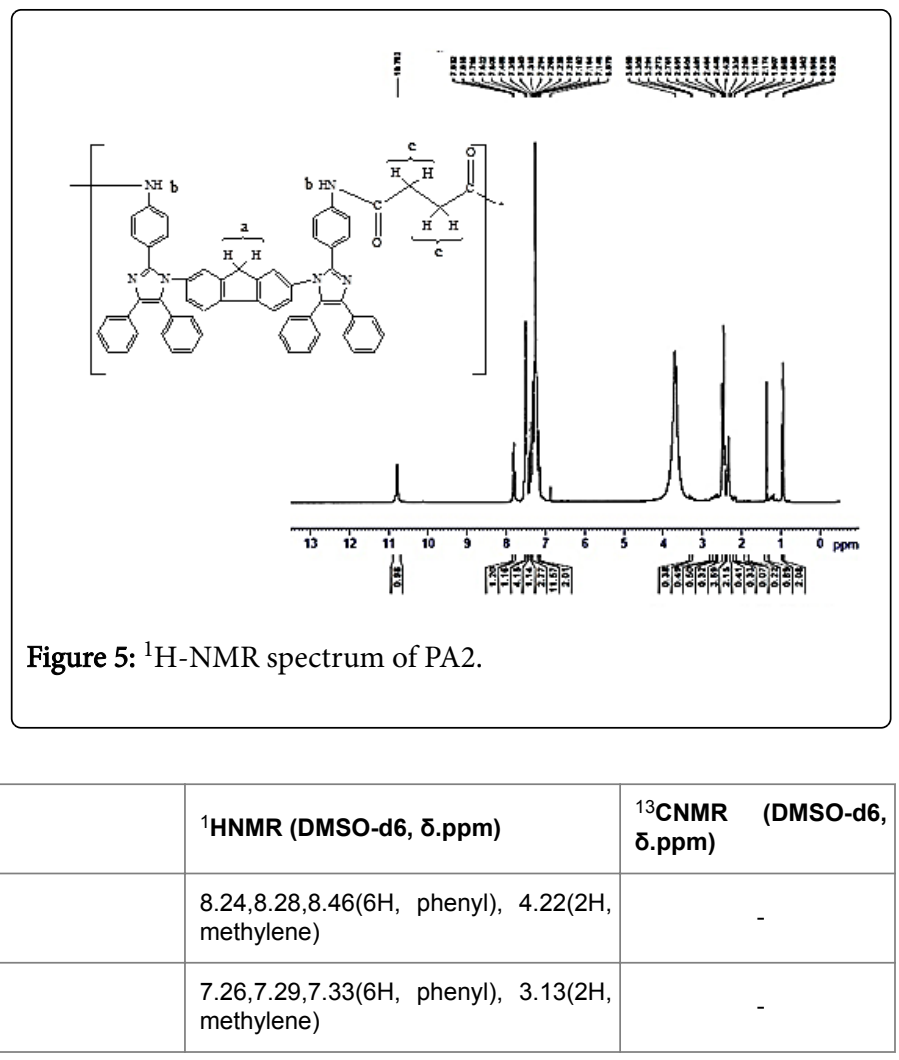


Citation: Sadeghinia A, Mighani H (2018) Synthesis and Study of Thermo Stability Properties of Novel Polyamides. J Enviorn Anal Chem 5: 241. doi:10.4172/2380-2391.1000241

Page 5 of 6

\begin{tabular}{|c|c|c|c|}
\hline Monomer (3) & $3088,2917(\mathrm{Ar}-\mathrm{H}), 1344,1529\left(\mathrm{NO}_{2}\right), 1539(\mathrm{C}=\mathrm{C})$ & - & - \\
\hline Monomer (4) & $\begin{array}{l}3306,3347(\mathrm{NH} 2), \mathrm{LH} 42919,3033(\mathrm{Ar}-\mathrm{H}), 1634(\mathrm{C}=\mathrm{N}), 1472(\mathrm{C}=\mathrm{C}), 1297(\mathrm{C}- \\
\mathrm{N})\end{array}$ & $\begin{array}{l}\text { 6.41-7.82(34H, phenyl }), \quad 5.2(4 \mathrm{H}, \\
\text { amine }), 1.77,1.93(2 \mathrm{H} \text {, methylene })\end{array}$ & $\begin{array}{l}\text { 113-148(54C, phenyl), } \\
30.38 \text { (2C, methylene) }\end{array}$ \\
\hline
\end{tabular}

Table 1: Spectra data results of monomers.

\begin{tabular}{|c|c|c|c|c|c|}
\hline \multirow{3}{*}{ PAIR(KBr, $\left.\mathrm{cm}^{-1}\right)^{1} \mathrm{HNMR}$ (DMSO-d6, ס.ppm) } & \multicolumn{5}{|c|}{ Elemental analysis } \\
\hline & \multicolumn{5}{|c|}{ CalcFound } \\
\hline & C & H & NC & H & $\mathbf{N}$ \\
\hline 3362(NH),1629 1.91,2.18(2H, methylene), & \multirow{3}{*}{4.64} & \multirow{3}{*}{8.48} & \multirow{3}{*}{82.48} & \multirow{3}{*}{4.95} & \multirow{3}{*}{9.01} \\
\hline PA1 $(\mathrm{C}=0), 1170,1104,5.89(2 \mathrm{H}$, amide $), 6.74-7.48,83.63$ & & & & & \\
\hline $1061(\mathrm{C}=\mathrm{C})(42 \mathrm{H}$, phenyl) & & & & & \\
\hline 3390(NH),1644 0.93,1.3(2H, methylene), & \multirow{3}{*}{4.18} & \multirow{3}{*}{9.77} & \multirow{3}{*}{83.58} & \multirow{3}{*}{5.03} & \multirow{3}{*}{9.83} \\
\hline PA2(C=O),1269(C-N) 2.3(4H, methylene),6.7-7.4, 82.32 & & & & & \\
\hline (34H, phenyl), $10.7(2 \mathrm{H}$, amide) & & & & & \\
\hline \multicolumn{6}{|c|}{ Aromatic hydrogen } \\
\hline $3304(\mathrm{NH}), 1637$ & \multirow{3}{*}{4.59} & \multirow{3}{*}{9.19} & \multirow{3}{*}{81.95} & \multirow{3}{*}{5.03} & \multirow{3}{*}{9.95} \\
\hline PA3 $(C=0), 1444,1495,-82.71$ & & & & & \\
\hline$(\mathrm{C}=\mathrm{C}), 1285(\mathrm{C}-\mathrm{N})$ & & & & & \\
\hline 3298(NH), 1661 & \multirow{3}{*}{5.14} & \multirow{3}{*}{9.39} & \multirow{3}{*}{82.56} & \multirow{3}{*}{5.84} & \multirow{3}{*}{9.76} \\
\hline PA4 $(C=0), 1446,1503,-81.88$ & & & & & \\
\hline$(\mathrm{C}=\mathrm{C}), 1279(\mathrm{C}-\mathrm{N})$ & & & & & \\
\hline
\end{tabular}

Table 2: Spectra data and elemental analysis results of polyamides.

Solubility of PAs: One of the main goals of this investigation was to prepare Schiff base polyamides with enhanced solubility. For solubility test, $50 \mathrm{mg}$ of polymer was dissolved in the solvents listed in Table 3. PA2 and PA4 are more soluble compared to the others. Easier solubility of these polymers in weaker solvents is due to aliphatic groups existing in polymer structure, as these groups enhance the flexibility of the chains. Comparison of PA1 and PA3 solubility proved more presence of phenyl groups in PA1, due to lower solubility of PA1.

\begin{tabular}{|l|l|l|l|l|l|l|l|}
\hline PA & NMP & DMF & DMSO & DMAC & THF & Acetone & Methanol \\
\hline PA1 & - & - & - & - & - & - & - \\
\hline PA2 & + & + & + & \pm & - & - & - \\
\hline PA3 & + & - & \pm & - & - & - & - \\
\hline PA4 & + & + & + & + & - & - & - \\
\hline
\end{tabular}

Table 3: Solubility of the polyamides where Soluble (+); partially soluble ( \pm ); insoluble (-); Solubility tested with $50 \mathrm{mg}$ of polymer in 10 $\mathrm{mL} \quad$ of solvent; $\quad \mathrm{NMP}=\mathrm{N}$-methylpyrolidone; DMF=Dimethylformamide; THF=Tetrahydrofurane.
Thermal properties of PAs: Thermal stability of the PA1 and PA3 has been investigated by TGA measurements under $\mathrm{N}_{2}$ atmosphere at heating rate of $10 \mathrm{~K} / \mathrm{min}$. Initial weight loss $\left(\mathrm{T}_{0}\right)$ below $150^{\circ} \mathrm{C}$ is related to the surface water desorption. $10 \%$ weight loss occurred in the region of $400-450^{\circ} \mathrm{C}$. Mass of the rest polymers at $600^{\circ} \mathrm{C}$ was in the range of $48-50 \%$. Results are presented in Table 4 . As results illustrate, PA1 is more thermal resistant than PA3. While polymer temperature ascends, chemical bonding will start to vibration and by increasing the temperature, the bonding vibrations will increase till the degradation starts. It can be concluded that, phenyl groups in polymer result in higher thermal resistivity and rigidity of the polymer. PA1 has higher thermal resistance compared to the PA2 because it has one phenyl group more than PA2.

\begin{tabular}{|l|l|l|l|}
\hline PA & $\mathbf{T}_{10} \%\left({ }^{\circ} \mathbf{C}\right) \mathbf{a}$ & $\mathbf{T}_{20} \%\left({ }^{\circ} \mathbf{C}\right) \mathbf{b}$ & $\%$ Ch.Y.c \\
\hline PA1 & 443 & 487 & 50 \\
\hline PA2 & 414 & 461 & 48 \\
\hline
\end{tabular}

Table 4: Data of TGA where a: $10 \%$ weight loss, b: $20 \%$ weight loss, c: The char yields of the polyamides at 600 . 
Citation: Sadeghinia A, Mighani H (2018) Synthesis and Study of Thermo Stability Properties of Novel Polyamides. J Enviorn Anal Chem 5: 241. doi:10.4172/2380-2391.1000241

Page 6 of 6

\section{Conclusion}

Four new Schiff-base polyamides were synthesized from the reaction of a novel diamine monomer $\left(\mathrm{LH}_{4}\right)$ with dicarboxylic acid and dichlorides. Thermal properties of these polyamides were studied by TGA. The char yields of these polyamides at $600^{\circ} \mathrm{C}$ were in the range of $48 \%-50 \%$, showed their excellent thermal resistance. The bulky phenyl groups in the polyamides caused the enhanced thermal resistance and introduction of aliphatic groups into polyamides chain resulted in improved solubility.

\section{References}

1. Civilica (2018) Effect of EDTA (ethylene diamine tetra-acetic acid) and municipal solid waste compost on different levels of lead and cadmium in the soil and phytoremediation these elements by sunflower plant.

2. Peruncheralathan S, Henze M, Schneider C (2007) Scandium triflate catalyzed aminolysis of meso-aziridines. Synlett 14: 2289-2291.

3. Ghorai MK, Sahoo AK, Kumar S (2011) Synthetic Route to Chiral Tetrahydroquinoxalines via Ring-Opening of Activated Aziridines. Org Lett 13: 5972-5975.

4. Röben C, Souto JA, Escudero-Adán EC, Muñiz K (2013) Oxidative Diamination Promoted by Dinuclear Iodine (III) Reagents. Org Lett 15: 1008-1011.
5. Zhao B, Yuan W, Du H, Shi Y (2007) Cu (I)-Catalyzed Intermolecular Diamination of Activated Terminal Olefins. Org Lett 9: 4943-4945.

6. Zhao B, Peng X, Cui S, Shi Y (2010) Cu(I)-Catalyzed Regioselective Diamination of Conjugated Dienes via Dual Mechanistic Pathways. J Am Chem Soc 132: 11009-11011.

7. Xu J, Du H, Shi Y (2007) Diamination of Conjugated Dienes and Trienes Catalyzed by N-Heterocyclic Carbene- $\mathrm{Pd}(0)$ Complexes. J Org Chem 72: 7038-7041.

8. Du H, Yuan W, Zhao B, Shi Y (2007) A Pd(0)-Catalyzed Diamination of Terminal Olefins at Allylic and Homoallylic Carbons via Formal C-H Activation under Solvent-Free Conditions. J Am Chem Soc 129: 7496-7497.

9. Cornwall RG, Zhao B, Shi Y (2013) Catalytic Asymmetric Synthesis of Cyclic Sulfamides from Conjugated Dienes. Org Lett 15: 796-799.

10. Sibbald PA, Michael FE (2009) Palladium-Catalyzed Diamination of Unactivated Alkenes Using N-Fluorobenzenesulfonimide as Source of Electrophilic Nitrogen. Org Lett 11: 1147-1149.

11. Streuff J, Hövelmann CH, Nieger M, Muniz K (2005) Palladium(II)Catalyzed Intramolecular Diamination of Unfunctionalized Alkenes. J Am Chem Soc 127: 14586-14587. 